Miloš Stojanović, ${ }^{1}$ Mirjana Stojković, Marija Miletić, Biljana Beleslin, Nata Joksimović, Jasmina Ćirić, Miloš Žarković

\title{
ULOGA MONITORINGA KRVNOG PRITISKA U KLINIČKOJ PRAKSI
}

\begin{abstract}
Abstrakt: Uloga i preporuke za monitoring krvnog pritiska (ABPM). Koje uređaje i softver koristiti. Kako se programiraju uređaji. Normalne vrednosti krvnog pritiska za dan i noć i kako analizirati i koristiti dobijene podatke u kliničkoj praksi. ABPM je potpuno automatizovana tehnika u kojoj se meri krvni pritisak (KP) u pravilnim intervalima (obično svakih 15 do 30 minuta) tokom 24 sata, pružajući vrednosti KP tokom normalnih dnevnih aktivnosti pacijenta. Pojedini specijalisti predlažu upotrebu ABPM-a za postavljanje prve dijagnoze hipertenzije i za donošenje odluka o lečenju. National Institute for Health and Clinical Excellence u Velikoj Britaniji preporučio je da se ABPM uradi svim ljudima za koje se sumnja da imaju hipertenziju. Analizom diunarnih promena krvnog pritiska pomoću ABPM-a možemo proceniti kardiovaskularni morbiditet i mortalitet, predviđajući ozbiljnost i prognozu bolesti kod pacijenta sa značajnim kardiovaskularnim rizikom. Za upotrebu ABPM-a preporučuju se samo provereni uređaji. Najčešće se ABPM koristi da se vidi da li osoba ima hipertenziju belih mantila, a u preporukama se preporučuje za otkrivanje maskirane hipertenzije, procene variranja krvnog pritiska tokom $24 \mathrm{~h}$ i dijagnozu hipotenzije. Neophodna je obuka kako se koristi ABPM koja može biti deo programa redovne nastave Medicinskog fakulteta, kongresa ili radionice. U poslednjih nekoliko decenija dosta studija nalazi da srednja vrednost KP koja se dobija pomoću ABPM-a ima veću prediktivnu vrednost za kardiovaskularni rizik u odnosu na standardno merenje krvnog pritiska.
\end{abstract}

Ključne reči: monitoring krvnog pritiska, ABPM, upotreba, analiza

\section{Uvod}

Monitoring krvnog pritiska je potpuno automatizovana tehnika gde se meri krvni pritisak u pravilnim intervalima (obično svakih 15 do 30 minuta) tokom perioda od 24 sata, pružajući vrednosti KP tokom normalnih dnevnih aktivnosti pacijenta. (1)

1 Miloš Stojanović, Klinika za endokrinologiju, dijabetes i bolesti metabolizma, Klinički centar Srbije, email specmedico@gmail.com 
National Institute for Health and Clinical Excellence u Velikoj Britaniji preporučio je da se ABPM uradi svim ljudima za koje se sumnja da imaju hipertenziju. (2)

\section{Kliničke indikacije za ABPM su:}

Otkrivanje osoba sa hipertenzijom belih mantila.

Hipertenzija belih mantila kod nelečenih pacijenata;

Efekat belog mantila kod lečenih ili nelečenih pacijenata;

Lažna rezistentna hipertenzija kod lečenih pacijenata;

Otkrivanje osoba sa maskiranom hipertenzijom;

Maskirana hipertenzija kod nelečenih pacijenata;

Maskirana nekontrolisana hipertenzija kod lečenih pacijenata;

Otkrivanje izmenjenog diunarnog ritma;

Hipertenzija tokom dana;

Niži pritisak tokom popodnevnog odmora i posle obroka;

Hipertenzija tokom noći;

Da li postoji pad KP tokom sna;

Jutarnja hipertenzija i jutarnji porast KP;

Obstructive sleep apnea - veće vrednosti KP tokom sna;

Povećana varijabilnost krvnog pritiska;

Procena lečenja;

Povećana varijabilnost krvnog pritiska prilikom lečenja;

Procena KP tokom 24h;

Otkrivanje rezistentne hipertenzije;

Procena KP kod starijih osoba;

Procena KP kod dece i adolescenata;

Procena KP u trudnoći;

Procena KP kod visoko rizičnih pacijenata;

Otkrivanje hipotenzije;

Procena KP u Parkinsonovoj bolesti;

Endokrina hipertenzija;

\section{Odabir ABPM uređaja}

Bitno je da ABPM uređaj meri tačno krvni pritisak. Uređaji se testiraju u centrima u svetu i informaciju o kvalitetu uređaja imate na više internet adresa, kao što su:

www.pressionearteriosa.net;

www.bihsoc.org;

www.medaval.org, www.dableducational.org. 


\section{Odabir odgovarajuće manžetne je veoma bitan.}

Važno je da odaberete manžetnu odgovarajuće veličine, odgovarajuće dužine i širine za ruku na kojoj treba da se postavi manžetna ABPM uređaja. Više studija je pokazalo da neadekvatna veličina manžetne dovodi do netačnog merenja krvnog pritiska. Na svakoj manžetni dat je podatak za koji obim nadlaktice je predviđena. Manžetna se postavlja na ruku koja se manje koristi. Ako postoji velika razlika u krvnom pritisku između ruku, tada se manžetna postavlja na ruku gde je izmeren veći krvni pritisak.

\section{Postavljanje ABPM-a}

Veoma je bitno da se objasni osobi koja nosi ABPM kako radi uređaj i kako da se ponaša dok nosi aparat $\mathrm{i}$ kako da piše dnevnik aktivnosti. U kliničkoj praksi najbolje je da se osoba ponaša kao i svaki dan. Učestalost merenja tokom 24-časovnog perioda uglavnom nije veća od $15 \mathrm{~min}$, niti manja od $30 \mathrm{~min}$. Osoba se savetuje da ne mrda ruku tokom merenja. Na kraju merenja podaci se preuzimaju u računarski softver kao što je „DABL“ radi dobijanja rezultata (3). Osoba koji nosi uređaj popunjava u dnevnik aktivnosti: vreme veće aktivnosti, bilo kakvi simptomi, vremena buđenja i spavanja, periodi stresa, vreme obroka i lekove koje je uzimala. Da bi se ABPM mogao tumačiti neophodno je da ima 70\% uspešnih merenja ili najmanje 14 očitavanja dobijenih tokom dnevnog perioda ili najmanje 7 očitavanja tokom noćnog perioda.

\section{Analiza i tumačenje ABPM podataka}

Softver za analizu podataka ABPM-a trebalo bi da obezbedi standardizovani format crteža sa svim merenjima KP na vertikalnoj osi i doba dana na vodoravnoj osi, sa različitim prozorima $24 \mathrm{~h}$ perioda i normalnim opsezima KP. Statistiku prosečnog sistolnog i dijastolnog KP za 24h, period tokom dana i period tokom sna.

Prosečne vrednosti KP tokom 24 sata, tokom dana i tokom sna su važni parametri dobijeni iz ABPM snimaka.

NICE preporuke, JNC 7 preporuke, ESH / ESC preporuke i rezultati studija, kao što su IDACO i Ohasama, doprineli su definisanju gornjih prosečnih vrednosti za ABPM: 24h prosečno 130 / 80 $\mathrm{mmHg}$, budan (dan) prosečno 135 / 85mmHg, a spavanje (noćno) prosečno $120 / 70 \mathrm{mmHg}$.

Pickering (4) je predložio naziv „hipertenzija belih mantila“ za KP veći od 140/90 mmHg meren u ordinaciji, a srednji ABPM je manji od 135/85 mmHg u proseku. Ako osoba ima „hipertenziju belih mantila“ tada nije potrebna terapija već pažljivije praćenje pacijenta. 
„Efekat belog mantila“ definisan je kao skok KP u medicinskom okruženju bez obzira na dnevnu vrednost ABPM-a ili upotrebu lekova.

Definicija maskirane hipertenzije je da je KP u ordinaciji u granici normale a ABPM nalazi veće prosečne vrednosti KP od 135/85 mmHg. (5) Osobe sa maskiranom hipertenzijom imaju povećan rizik od oštećenja ciljnih organa i kardiovaskularnih bolesti.

U fiziološkim uslovima postoji pad krvnog pritiska za vreme sna za oko $10 \%$ i te osobe se nazivaji „dipperi“. Osobe kod kojih nema pada krvnog pritiska tokom sna se nazivaju „nondipperi“ $\mathrm{i}$ imaju povećan kardiovaskularni rizik. Povećanje KP tokom sna može ukazivati na pojavu stenoze koronarnih arterija, slabije kognitivne performanse, hipertrofiju leve komore, oštećenja bubrega, endokrine hipertenzije ili obstructive sleep apnea. Karakteristično je za obstructive sleep apnea da su veće vrednosti ABPM-a tokom sna u odnosu na vrednosti ABPM-a tokom dana.

Pacijenti sa većim vrednostima krvnog pritiska tokom sna imaju veliki kardiovaskularni rizik. (6) Pacijenti sa povećanom varijabilnošću KP često imaju efekat belih mantila ili maskiranu hipertenziju i oni su izloženi većem kardiovaskularnom riziku.

Nestabilni krvni pritisak ukazuje da nije dobra antihipertenzivna terapija i time nam ABPM ukazuje na efikasnost lečenja krvnog pritiska.

Studije pokazuju da je ABPM nezavisni pokazatelj stepena rizika za kardiovaskularne događaje, što sugeriše da je ABPM koristan u stratifikaciji rizika kod pacijenata sa rezistentnom hipertenzijom.

Studije za procenu KP u trudnoći nalaze da ABPM ima važnu ulogu u otkrivanju hipertenzije belih mantila i pokazatelj je rizika od razvoja hipertenzije i eklampsije kasnije u trudnoći.

Pokazali smo vrednost ABPM-a u kliničkoj praksi u nadi da će lekari videti da tehnika ima veliku ulogu u dijagnozi hipertenzije, proceni variranja krvnog pritiska, proceni efikasnosti terapije za krvni pritisak, čime se poboljšava kontrola KP i smanjuju kardiovaskularne posledice neregulisanog krvnog pritiska.

\section{Reference}

1. Pickering TG., Shimbo D., Haas D. Ambulatory blood-pressure monitoring. N Engl J Med. 2006; 354(22): 2368-74.

2. National Institute for Health and Clinical Excellence (NICE). Hypertension.

The clinical management of primary hypertension in adults.

Clinical Guideline 127; 2011. www.nice.org.uk/guidance/CG127.

3. O’Brien E., Parati G., Stergiou G., Asmar R., Beilin L., Bilo G., et al. European Society of Hypertension position paper on ambulatory blood pressure monitoring. J Hypertens. 2013; 31(9): 1731-68. 
4. Pickering TG., James GD., Boddie C., Harshfield GA., Blank S., Laragh JH. How common is white coat hypertension? JAMA 1988; 259: 225- 228.

5. Pickering T., Davidson K., Gerin W., Schwartz JE. Masked hypertension. Hypertension 2002; 40: 795-796.

6. Ohkubo T., Hozawa A., Yamaguchi J., Kikuya M., Ohmori K., Michimata M., et al. Prognostic significance of the nocturnal decline in blood pressure in individuals with and without high 24-h blood pressure: the Ohasama study. J Hypertens 2002; 20: 2183-2189. 